\title{
Vital Signs: Trends in Incidence of Cancers Associated with Overweight and Obesity — United States, 2005-2014
}

\author{
C. Brooke Steele, DO ${ }^{1}$; Cheryll C. Thomas, $\mathrm{MSPH}^{1}$; S. Jane Henley, MSPH${ }^{1}$; Greta M. Massetti, $\mathrm{PhD}^{1}$; Deborah A. Galuska, PhD ${ }^{2}$; \\ Tanya Agurs-Collins, $\mathrm{PhD}^{3}$; Mary Puckett, $\mathrm{PhD}^{1}$; Lisa C. Richardson, $\mathrm{MD}^{1}$
}

On October 3, 2017, this report was posted as an MMWR Early Release on the MMWR website (https://www.cdc.gov/mmwr).

\section{Abstract}

Background: Overweight and obesity are associated with increased risk of at least 13 different types of cancer.

Methods: Data from the United States Cancer Statistics for 2014 were used to assess incidence rates, and data from 2005 to 2014 were used to assess trends for cancers associated with overweight and obesity (adenocarcinoma of the esophagus; cancers of the breast [in postmenopausal women], colon and rectum, endometrium, gallbladder, gastric cardia, kidney, liver, ovary, pancreas, and thyroid; meningioma; and multiple myeloma) by sex, age, race/ethnicity, state, geographic region, and cancer site. Because screening for colorectal cancer can reduce colorectal cancer incidence through detection of precancerous polyps before they become cancerous, trends with and without colorectal cancer were analyzed.

Results: In 2014, approximately 631,000 persons in the United States received a diagnosis of a cancer associated with overweight and obesity, representing $40 \%$ of all cancers diagnosed. Overweight- and obesity-related cancer incidence rates were higher among older persons (ages $\geq 50$ years) than younger persons; higher among females than males; and higher among non-Hispanic black and non-Hispanic white adults compared with other groups. Incidence rates for overweightand obesity-related cancers during 2005-2014 varied by age, cancer site, and state. Excluding colorectal cancer, incidence rates increased significantly among persons aged 20-74 years; decreased among those aged $\geq 75$ years; increased in 32 states; and were stable in 16 states and the District of Columbia.

Conclusions: The burden of overweight- and obesity-related cancer is high in the United States. Incidence rates of overweight- and obesity-related cancers except colorectal cancer have increased in some age groups and states.

Implications for Public Health Practice: The burden of overweight- and obesity-related cancers might be reduced through efforts to prevent and control overweight and obesity. Comprehensive cancer control strategies, including use of evidencebased interventions to promote healthy weight, could help decrease the incidence of these cancers in the United States.

\section{Introduction}

In 2013-2014, approximately one third of adults in the United States were overweight (body mass index [BMI] $25.0-29.9 \mathrm{~kg} / \mathrm{m}^{2}$ ) and approximately one third had obesity $\left(\mathrm{BMI} \geq 30 \mathrm{~kg} / \mathrm{m}^{2}\right)(1)$. Approximately half of U.S. residents are unaware that adults who are overweight or have obesity are at increased risk for cancer $(2,3)$. The International Agency for Research on Cancer (IARC) states that there is sufficient evidence for an association with excess body fatness, including overweight, obesity, and weight gain, and at least 13 cancers (3). These cancers include adenocarcinoma of the esophagus; cancers of the breast (in postmenopausal women), colon and rectum, endometrium (corpus uterus), gallbladder, gastric cardia, kidney (renal cell), liver, ovary, pancreas, and thyroid; meningioma, and multiple myeloma. Overweight and obesity might increase cancer risk through induction of metabolic and endocrine abnormalities, including increases in inflammation and levels of insulin, insulin-like growth factor, and sex hormones (4).

Data compiled for the United States Cancer Statistics (USCS) data set (https://nccd.cdc.gov/uscs/) were used to calculate incidence rates in 2014 and trends during 2005-2014 for cancers associated with overweight and obesity (overweightand obesity-related cancers). In this report, overweight- and obesity-related cancers were defined as those classified by IARC as having sufficient evidence for an association with excess body fatness.

\section{Methods}

The USCS is a compilation of data from multiple sources that is used to report official federal cancer statistics through the USCS web-based report. The USCS data set includes 


\section{Key Points}

- Overweight and obesity are associated with increased risk of at least 13 different types of cancer.

- Overweight- and obesity-related cancers accounted for $40 \%$ of all cancers diagnosed in 2014.

- About $55 \%$ of cancers diagnosed in women and $24 \%$ of those diagnosed in men are overweight- and obesityrelated cancers.

- The incidence of overweight- and obesity-related cancers (excluding colorectal cancer) increased significantly among persons aged 20-74 years during 2005-2014.

- The findings emphasize the importance of intensifying nationwide efforts to prevent and treat overweight and obesity.

- Multilevel approaches to comprehensive cancer control that address social determinants of health and include evidence-based interventions that address healthy weight and other cancer risk factors might help reduce the burden of cancer and other chronic diseases.

- Additional information is available at https://www.cdc.gov/ vitalsigns/.

cancer incidence data from CDC's National Program of Cancer Registries (NPCR) and the National Cancer Institute's Surveillance, Epidemiology, and End Results (SEER) program. Data on new cancer cases diagnosed during 2005-2014 were obtained from population-based cancer registries affiliated with NPCR and SEER programs in each state and the District of Columbia (DC). Data from DC and all states met USCS publication criteria for 2014 , covering $100 \%$ of the U.S. population; all states except Nevada met USCS publication criteria each year during 2005-2014, covering approximately $99 \%$ of the U.S. population.* Cancer site for cases was classified by anatomic site and histology. ${ }^{\dagger}$ Only cases of invasive cancer were included. Postmenopausal breast cancer was defined as breast cancer diagnosed in women aged $\geq 50$ years.

\footnotetext{
* Cancer registries demonstrated that cancer incidence data were of high quality by meeting five United States Cancer Statistics publication criteria: 1) $\leq 5 \%$ of cases ascertained solely on the basis of death certificate; 2 ) $\leq 3 \%$ of cases missing information on sex; 3 ) $\leq 3 \%$ of cases missing information on age; 4 ) $\leq 5 \%$ of cases missing information on race; and 5) $\geq 97 \%$ of registry's records passed a set of single-field and inter-field computerized edits that test the validity and logic of data components (https://www.cdc.gov/cancer/npcr/uscs/technical_ notes/criteria.htm).

$\dagger$ Cases were first classified by anatomic site using the International Classification of Diseases for Oncology, Third Edition (http://codes.iarc.fr/) then cases with hematopoietic histologies were classified using the World Health Organization Classification of Tumours of Haematopoietic and Lymphoid Tissues, Fourth Edition (http://www.bloodjournal.org/content/117/19/5019?sso-checked=true\#T1).
}

Population estimates for rate denominators were a modification of annual county population estimates by age, sex, bridged-race, and ethnicity, produced by the U.S. Census Bureau in collaboration with CDC and with support from National Cancer Institute, and aggregated to the state and national levels. ${ }^{\S}$ Race bridging is a method used to make multiple-race and single-race data collection systems sufficiently comparable to permit estimation and analysis of race-specific statistics (https://www.cdc.gov/nchs/data/series/ sr_02/sr02_135.pdf). Ninety-five percent confidence intervals for rates are presented to allow for informal comparisons among rates, without specifying a referent group. Joinpoint regression (https://surveillance.cancer.gov/joinpoint/), which allowed different slopes for more than one period, was used to calculate changes in rates; trends were quantified by average annual percent change. Because screening for colorectal cancer can reduce colorectal cancer incidence through detection of precancerous polyps before they become cancerous (https:// www.uspreventiveservicestaskforce.org/Page/Document/ UpdateSummaryFinal/colorectal-cancer-screening2?ds), trends with and without colorectal cancer were analyzed. Rates were estimated by sex, age, race/ethnicity, and U.S. Census region. Trends were age-adjusted and estimated by cancer site, sex, and state. To examine the impact of the change in rates, the number of cases expected during 2006-2014 if rates had remained at 2005 levels was subtracted from the actual number of cases during this period.

\section{Results}

In 2014, approximately 631,604 persons in the United States received a diagnosis of an overweight- or obesity-related cancer (Table 1). This represents $40 \%$ of the nearly 1.6 million cancers diagnosed each year $(55 \%$ of the 799,734 cancers among women and $24 \%$ of the 796,752 cancers among males). Overweight- and obesity-related cancer incidence rates were higher among older persons (ages $\geq 50$ years) than younger persons and two thirds of cases occurred among persons aged 50-74 years. The overweight- and obesity-related cancer incidence rate was higher among females (218.1 per 100,000 population) than among males (115.0 per 100,000$)$, partially because endometrial, ovarian, and postmenopausal female breast cancers accounted for $42 \%(268,091)$ of overweightand obesity-related cancers. The rates also varied by race/ ethnicity, with higher incidence among non-Hispanic blacks (black) and non-Hispanic whites (white) compared with other groups; however, black males and American Indian/Alaska Native males had higher incidence rates than did white males.

\footnotetext{
$\$$ Population estimates incorporate bridged single-race estimates derived from the original multiple race categories in the 2010 U.S. Census (https://seer. cancer.gov/popdata/index.html).
} 
TABLE 1. Number and annual age-adjusted rate* of overweight- and obesity-related invasive cancer cases, ${ }^{\dagger}$ by selected characteristics United States, $\$ 2014$

\begin{tabular}{|c|c|c|c|c|c|c|}
\hline \multirow[b]{2}{*}{ Characteristic } & \multicolumn{2}{|r|}{ Total } & \multicolumn{2}{|r|}{ Males } & \multicolumn{2}{|c|}{ Females } \\
\hline & No. & Rate $(95 \% \mathrm{Cl})$ & No. & Rate $(95 \% \mathrm{Cl})$ & No. & Rate $(95 \% \mathrm{CI})$ \\
\hline Total & 631,604 & $169.7(169.3-170.1)$ & 194,727 & $115.0(114.5-115.5)$ & 436,877 & $218.1(217.4-218.7)$ \\
\hline \multicolumn{7}{|l|}{ Age group (yrs) } \\
\hline$<20$ & 2,230 & $2.7(2.6-2.8)$ & 719 & $1.7(1.6-1.8)$ & 1,511 & $3.8(3.6-4.0)$ \\
\hline $20-49$ & 60,386 & $47.2(46.8-47.6)$ & 20,884 & $32.5(32.1-32.9)$ & 39,502 & $62.1(61.4-62.7)$ \\
\hline $50-64$ & 240,299 & $383.6(382.0-385.1)$ & 71,518 & $235.3(233.6-237.0)$ & 168,781 & $523.3(520.8-525.8)$ \\
\hline $65-74$ & 173,764 & $658.4(655.3-661.5)$ & 54,313 & $440.0(436.3-443.7)$ & 119,451 & $850.3(845.5-855.2)$ \\
\hline$\geq 75$ & 154,925 & $782.1(778.2-786.0)$ & 47,293 & $592.1(586.8-597.5)$ & 107,632 & 910.4 (904.9-915.8) \\
\hline \multicolumn{7}{|l|}{ Race/Ethnicity } \\
\hline White & 470,789 & $170.9(170.4-171.4)$ & 144,456 & $114.2(113.6-114.8)$ & 326,333 & $222.3(221.5-223.1)$ \\
\hline Black & 71,847 & $186.5(185.1-188.0)$ & 22,129 & $134.2(132.3-136.1)$ & 49,718 & $226.3(224.3-228.4)$ \\
\hline American Indian/Alaska Native & 3,970 & $162.5(157.2-167.9)$ & 1,376 & $121.9(115.1-129.0)$ & 2,594 & $197.3(189.5-205.3)$ \\
\hline Asian/Pacific Islander & 23,193 & $128.4(126.7-130.1)$ & 6,904 & $87.7(85.6-89.9)$ & 16,289 & $162.2(159.7-164.8)$ \\
\hline Hispanic & 55,778 & $150.6(149.3-152.0)$ & 17,990 & $108.8(107.1-110.6)$ & 37,788 & $188.0(186.0-189.9)$ \\
\hline \multicolumn{7}{|l|}{ Census region ${ }^{\dagger \dagger}$} \\
\hline Northeast & 127,436 & $185.3(184.2-186.3)$ & 37,739 & $122.8(121.5-124.0)$ & 89,697 & $239.2(237.6-240.9)$ \\
\hline Midwest & 140,687 & $173.8(172.9-174.8)$ & 43,173 & $117.6(116.5-118.7)$ & 97,514 & $224.1(222.7-225.6)$ \\
\hline South & 230,431 & $165.7(165.0-166.4)$ & 73,138 & $115.5(114.7-116.4)$ & 157,293 & $209.5(208.4-210.5)$ \\
\hline West & 133,050 & $159.7(158.8-160.6)$ & 40,677 & $105.5(104.5-106.6)$ & 92,373 & $208.9(207.5-210.3)$ \\
\hline
\end{tabular}

Abbreviation: $\mathrm{Cl}$ = confidence interval.

* Per 100,000 persons, age-adjusted to the 2000 U.S. standard population.

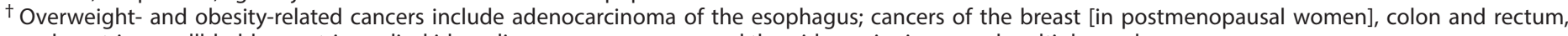
endometrium, gallbladder, gastric cardia, kidney, liver, ovary, pancreas, and thyroid; meningioma; and multiple myeloma.

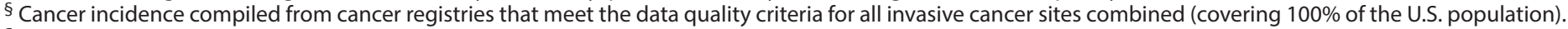

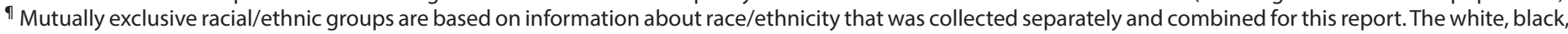

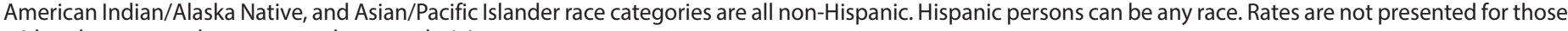
with unknown or other race or unknown ethnicity.

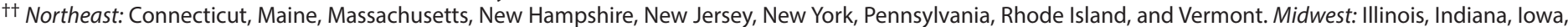

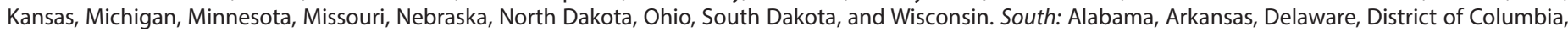

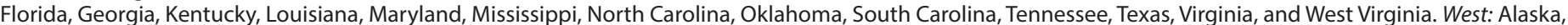
Arizona, California, Colorado, Hawaii, Idaho, Montana, Nevada, New Mexico, Oregon, Utah, Washington, and Wyoming.

Incidence was highest in the Northeast compared with other U.S. Census regions.

Among cancers affecting both males and females, incidence rates in 2014 were higher among males than among females for colorectal cancer (44.1 per 100,000 versus 33.7 per 100,000$)$, kidney cancer (20.9 versus 10.6), pancreatic cancer (14.4 versus 11.1$)$, liver cancer (11.2 versus 3.4$)$, adenocarcinoma of the esophagus (5.4 versus 0.8$)$, multiple myeloma (7.5 versus 4.9), and gastric cardia cancer (3.6 versus 0.8 ) (Table 2). Females had higher rates than did males of thyroid cancer (21.3 versus 7.4 ) and gallbladder cancer (1.4 versus 0.8$)$. Among the three overweight- and obesity-related cancers that affect females only, incidence rates were higher for postmenopausal breast cancer (92.6 per 100,000) than for endometrial cancer $(26.5$ per 100,000$)$ and ovarian cancer (11.0 per 100,000). By site, incidence rates decreased significantly each year for meningioma $(-3.8 \%$ per year), colorectal cancer $(-2.9 \%)$, and ovarian cancer $(-2.0 \%)$. Incidence rates increased significantly each year during this period for six cancers: thyroid cancer ( $4.0 \%$ per year), liver cancer $(2.9 \%)$, gastric cardia cancer $(1.2 \%)$, endometrial cancer $(1.1 \%)$, pancreatic cancer $(0.8 \%)$, and kidney cancer $(0.7 \%)$. The incidence rates were stable for adenocarcinoma of the esophagus, gallbladder cancer, multiple myeloma, and postmenopausal breast cancer. The increase in risk for cancer per $1 \mathrm{~kg} / \mathrm{m}^{2}$ increase in BMI ranged from $1 \%$ each for thyroid and ovarian cancers to $9 \%$ for adenocarcinoma of the esophagus.

During 2005-2014, declines were observed in the overall incidence of overweight- and obesity-related cancers (-2\%), colorectal cancer $(-23 \%)$, and cancers not known to be related to overweight and obesity (-13\%) (Table 2). Increased use of colorectal cancer screening tests likely contributed to the decline in colorectal cancer; when colorectal cancer was excluded from overweight- and obesity-related cancers, a $7 \%$ increase in overall incidence was observed. The trends varied substantially by age group: the rate for all overweight- and obesity-related cancers increased significantly among persons aged 20-49 years and 50-64 years, and decreased among those aged 65-74 years and $\geq 75$ years; colorectal cancer rates declined in all age groups except in persons aged 20-49 years; and rates for overweightand obesity-related cancers (excluding colorectal cancers) increased among all age groups except persons aged $\geq 75$ years (Figure 1). Because of reductions in colorectal cancer rates, approximately 224,800 cases have been averted since 2005 . 
TABLE 2. Age-adjusted incidence of overweight- and obesity-related invasive cancer, changes in rates, and estimated percent increase in cancer risk associated with change in BMI, by cancer site and sex - United States,* 2005 and 2014

\begin{tabular}{|c|c|c|c|c|c|c|}
\hline \multirow[b]{2}{*}{ Cancer site } & \multirow[b]{2}{*}{$\%$} & \multirow{2}{*}{$\frac{2005}{\operatorname{Rate}^{\dagger}(95 \% \mathrm{Cl})}$} & \multirow{2}{*}{$\frac{2014}{\operatorname{Rate}^{\dagger}(95 \% \mathrm{Cl})}$} & \multicolumn{2}{|c|}{ 2005-2014 } & \multirow{2}{*}{$\begin{array}{c}\% \\
\text { Increase in risk for } \\
\text { cancer per } 1 \mathrm{~kg} / \mathrm{m}^{2} \\
\text { increase in } \mathrm{BMI}\end{array}$} \\
\hline & & & & $\begin{array}{c}\% \\
\text { Change } \\
\text { in rates }\end{array}$ & $\begin{array}{l}\text { Average annual } \\
\text { percent change } \\
\text { in rates } \S\end{array}$ & \\
\hline Breast [in postmenopausal women] & 31 & $90.5(90.1-91.0)$ & $92.6(92.2-93.0)$ & 2 & 0.2 & 2 \\
\hline $\begin{array}{l}\text { Colon and rectum } \\
\text { Male } \\
\text { Female }\end{array}$ & 22 & $\begin{array}{l}49.7(49.4-49.9) \\
58.1(57.7-58.5) \\
43.1(42.8-43.4)\end{array}$ & $\begin{array}{l}38.4(38.2-38.6) \\
44.1(43.7-44.4) \\
33.7(33.4-34.0)\end{array}$ & $\begin{array}{l}-23 \\
-24 \\
-22\end{array}$ & $\begin{array}{l}-2.9^{\S} \\
-3.1^{\S} \\
-2.8^{\S}\end{array}$ & 2 \\
\hline $\begin{array}{l}\text { Kidney (renal cell) } \\
\text { Male } \\
\text { Female }\end{array}$ & 9 & $\begin{array}{l}14.4(14.2-14.5) \\
19.5(19.3-19.7) \\
10.2(10.0-10.3)\end{array}$ & $\begin{array}{l}15.4(15.2-15.5) \\
20.9(20.7-21.1) \\
10.6(10.4-10.7)\end{array}$ & $\begin{array}{l}7 \\
7 \\
4\end{array}$ & $\begin{array}{l}0.7^{\S} \\
0.7^{\S} \\
0.4\end{array}$ & 5 \\
\hline Endometrium (corpus uterus) (female only) & 8 & $23.9(23.7-24.1)$ & $26.5(26.3-26.8)$ & 11 & $1.1^{\S}$ & 8 \\
\hline $\begin{array}{l}\text { Thyroid } \\
\text { Male } \\
\text { Female }\end{array}$ & 8 & $\begin{array}{r}10.3(10.2-10.4) \\
5.3(5.1-5.4) \\
15.2(15.0-15.4)\end{array}$ & $\begin{array}{r}14.4(14.3-14.6) \\
7.4(7.2-7.5) \\
21.3(21.1-21.5)\end{array}$ & $\begin{array}{l}40 \\
40 \\
40\end{array}$ & $\begin{array}{l}4.0^{\S} \\
4.0^{\S} \\
4.0^{\S}\end{array}$ & 1 \\
\hline $\begin{array}{l}\text { Pancreas } \\
\text { Male } \\
\text { Female }\end{array}$ & 7 & $\begin{array}{l}11.7(11.6-11.9) \\
13.3(13.1-13.5) \\
10.5(10.3-10.6)\end{array}$ & $\begin{array}{l}12.6(12.5-12.7) \\
14.4(14.2-14.5) \\
11.1(10.9-11.2)\end{array}$ & $\begin{array}{l}7 \\
8 \\
6\end{array}$ & $\begin{array}{l}0.8^{\S} \\
0.8^{\S} \\
0.7^{\S}\end{array}$ & 2 \\
\hline $\begin{array}{l}\text { Multiple myeloma } \\
\text { Male } \\
\text { Female }\end{array}$ & 4 & $\begin{array}{l}5.6(5.5-5.7) \\
6.9(6.7-7.0) \\
4.6(4.5-4.8)\end{array}$ & $\begin{array}{l}6.0(6.0-6.1) \\
7.5(7.3-7.6) \\
4.9(4.8-5.0)\end{array}$ & $\begin{array}{l}8 \\
9 \\
6\end{array}$ & $\begin{array}{l}1.1 \\
1.2^{\S} \\
1.1^{\S}\end{array}$ & 2 \\
\hline $\begin{array}{l}\text { Liver } \\
\text { Male } \\
\text { Female }\end{array}$ & 4 & $\begin{array}{l}5.5(5.4-5.6) \\
8.8(8.6-8.9) \\
2.7(2.6-2.8)\end{array}$ & $\begin{array}{r}7.0(7.0-7.1) \\
11.2(11.0-11.3) \\
3.4(3.3-3.5)\end{array}$ & $\begin{array}{l}29 \\
28 \\
26\end{array}$ & $\begin{array}{l}2.9^{\S} \\
2.9^{\S} \\
2.5^{\S}\end{array}$ & 5 \\
\hline Ovary (female only) & 3 & $13.1(12.9-13.2)$ & $11.0(10.8-11.2)$ & -16 & $-2.0^{\S}$ & 1 \\
\hline $\begin{array}{l}\text { Adenocarcinoma of the esophagus } \\
\text { Male } \\
\text { Female }\end{array}$ & 2 & $\begin{array}{l}2.9(2.8-2.9) \\
5.5(5.4-5.7) \\
0.8(0.7-0.8)\end{array}$ & $\begin{array}{l}2.9(2.8-2.9) \\
5.4(5.2-5.5) \\
0.8(0.7-0.8)\end{array}$ & $\begin{array}{r}-1 \\
-3 \\
2\end{array}$ & $\begin{array}{l}-0.5 \\
-0.7^{\S} \\
-0.4\end{array}$ & 9 \\
\hline $\begin{array}{l}\text { Gastric cardia } \\
\text { Male } \\
\text { Female }\end{array}$ & 1 & $\begin{array}{l}1.9(1.9-2.0) \\
3.4(3.3-3.5) \\
0.8(0.7-0.8)\end{array}$ & $\begin{array}{l}2.1(2.0-2.1) \\
3.6(3.5-3.7) \\
0.8(0.8-0.9)\end{array}$ & $\begin{array}{l}8 \\
7 \\
6\end{array}$ & $\begin{array}{l}1.2^{\S} \\
1.1^{\S} \\
0.8^{\S}\end{array}$ & 4 \\
\hline $\begin{array}{l}\text { Gallbladder } \\
\text { Male } \\
\text { Female }\end{array}$ & 1 & $\begin{array}{l}1.1(1.1-1.2) \\
0.8(0.7-0.8) \\
1.4(1.4-1.5)\end{array}$ & $\begin{array}{l}1.1(1.1-1.2) \\
0.8(0.8-0.8) \\
1.4(1.3-1.5)\end{array}$ & $\begin{array}{r}-1 \\
3 \\
-1\end{array}$ & $\begin{array}{r}-0.1 \\
0.1 \\
-0.1\end{array}$ & 5 \\
\hline $\begin{array}{l}\text { Meningioma } \\
\text { Male } \\
\text { Female }\end{array}$ & $<1$ & $\begin{array}{l}0.1(0.1-0.2) \\
0.1(0.1-0.1) \\
0.2(0.1-0.2)\end{array}$ & $\begin{array}{l}0.1(0.1-0.1) \\
0.1(0.1-0.1) \\
0.1(0.1-0.1)\end{array}$ & $\begin{array}{l}-29 \\
-17 \\
-35\end{array}$ & $\begin{array}{l}-3.8^{\S} \\
-2.7 \S \\
-4.0^{\S}\end{array}$ & 4 \\
\hline All overweight- and obesity-related cancers & - & $173(173-174)$ & $170(169-170)$ & -2 & $-0.3^{\S}$ & - \\
\hline $\begin{array}{l}\text { All overweight- and obesity-related cancers } \\
\text { except colorectal cancer }\end{array}$ & - & $123(123-124)$ & $132(131-132)$ & 7 & $0.8^{\S}$ & - \\
\hline Cancers not related to overweight and obesity & - & $306(305-306)$ & $267(267-268)$ & -13 & $-1.4^{\S}$ & - \\
\hline
\end{tabular}

Abbreviations: $\mathrm{BMI}=$ body mass index calculated as weight in kilograms/height in meters squared $\left(\mathrm{kg} / \mathrm{m}^{2}\right) ; \mathrm{Cl}=$ confidence interval.

* Cancer incidence compiled from cancer registries that meet the data quality criteria for all invasive cancer sites combined for all years during the period 2005 to 2014 (covering $99 \%$ of the U.S. population).

† Per 100,000 persons, age-adjusted to the 2000 U.S. standard population.

$\S$ Significant at $p<0.05$. Trends were measured with average annual percent change in rates and were considered to increase or decrease if $p<0.05$; otherwise trends were considered stable.

" Based on relative risk estimates from pooled epidemiologic studies (reviewed in http://www.nejm.org/doi/full/10.1056/NEJMsr1606602) and in the World Cancer Research Fund Continuous Update Project (http://www.wcrforg/int/research-we-fund/continuous-update-project-cup).

However, during this same period, 211,800 excess cases from other overweight- and obesity-related cancers have occurred. Incidence rates of overweight- and obesity-related cancers (excluding colorectal cancer) increased significantly in 32 states $(0.3 \%-1.8 \%)$, and did not change in 16 states and the District of Columbia (Figure 2).

\section{Conclusions and Comments}

Overweight- and obesity-related cancers accounted for $40 \%$ of all cancers diagnosed in 2014, and varied substantially across demographic groups. Endometrial, ovarian, and postmenopausal female breast cancers accounted for $42 \%$ of new cases of overweight-and obesity-related cancers in 2014, 
FIGURE 1. Average annual percent change* in overweight- and obesity-related invasive cancer incidence rates ${ }^{\dagger}$ among adults - United States, ${ }^{\S}$ 2005-2014

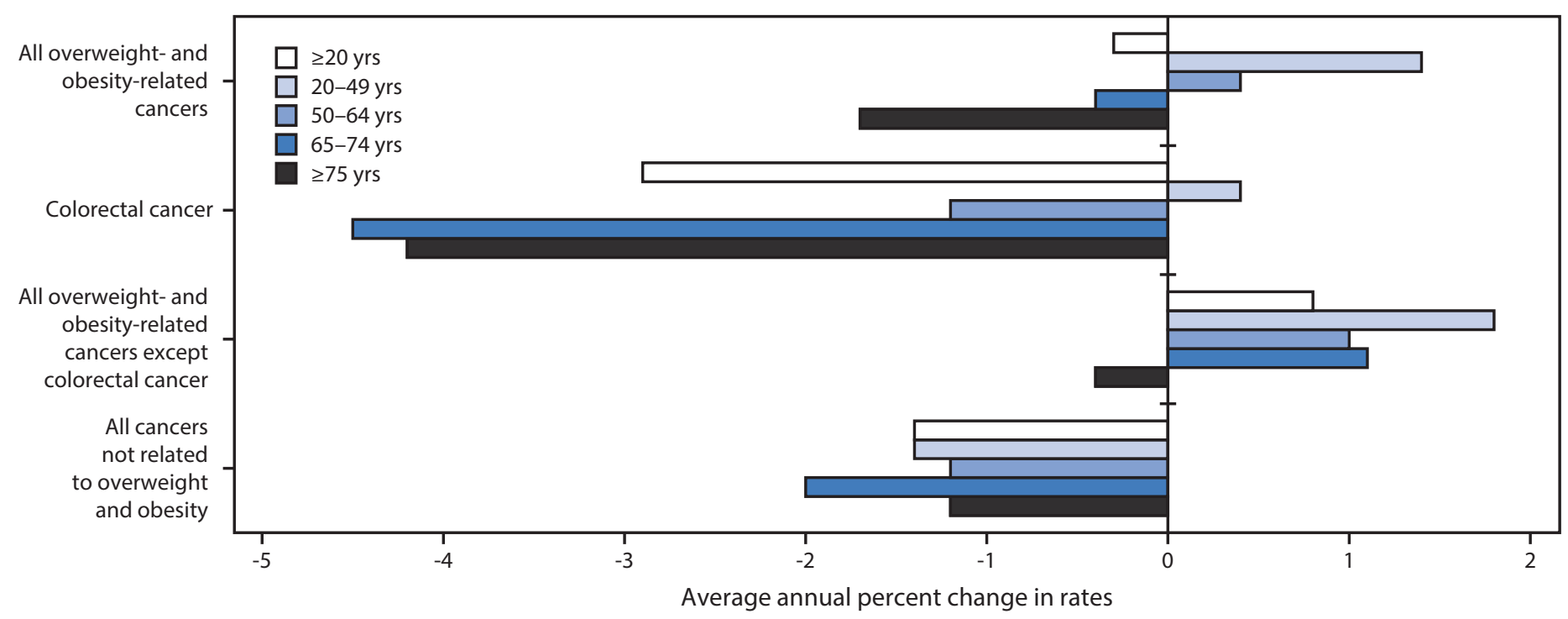

* Average annual percent change (AAPC) was calculated using joinpoint regression, which allowed different slopes for two periods; the year at which slopes changed could vary by age. All AAPCs were significantly different from zero $(p<0.05)$ except for colorectal cancer in persons aged 20-49 years.

† Overweight- and obesity-related cancer (adenocarcinoma of the esophagus; cancers of the breast [in postmenopausal women], colon and rectum, endometrium, gallbladder, gastric cardia, kidney, liver, ovary, pancreas, and thyroid; meningioma; and multiple myeloma) rates were calculated with and without colorectal cancer because colorectal cancer screening can detect precancerous polyps before they become cancerous, which might affect cancer incidence.

$\S$ Cancer incidence compiled from cancer registries that meet the data quality criteria for all invasive cancer sites combined for each year during the period $2005-2014$ (covering $99 \%$ of the U.S. population).

which is reflected in the higher overall incidence of overweightand obesity-related cancers among females. For cancers that occurred among both males and females, however, the incidence of most cancers was higher in males.

Meningioma declined the most $(-3.8 \%$ per year) during 2005-2014; however, this cancer accounted for $<1 \%$ of overweight- and obesity-related cancers among males and females. The second largest decline was in the rate of colorectal cancer, which accounted for approximately $22 \%$ of overweight- and obesity-related cancers; this trend likely influenced the overall decline in the incidence of overweight- and obesity-related cancers during 2005-2014. National data have demonstrated an increase in colorectal cancer screening (5), which might have contributed to the decline in colorectal cancer incidence through detection of precancerous polyps, which can then be removed before becoming cancerous. When colorectal cancer was excluded from the trend analysis, overweight- and obesity-related cancer incidence increased among all age groups except persons aged $\geq 75$ years. The increase in obesity-related cancer incidence coincides with an increase in the prevalence of obesity since 1960 in the United States with larger absolute percentage increases from 1960 to 2004 than from 2005 to 2014 (1). The prevalence of overweight during this later period remained stable. These historical and current trends in overweight and obesity and cancers related to excess weight reflect the continued need for public health strategies to prevent and control overweight and obesity in children and adults and help communities make it easier for people to be physically active and eat healthfully.

There is consistent evidence that a high BMI is associated with cancer risk. Persons who are overweight or have obesity are nearly twice as likely as are healthy-weight $\left(B M I=18.5-24.9 \mathrm{~kg} / \mathrm{m}^{2}\right)$ persons to develop adenocarcinoma of the esophagus and cancers of the gastric cardia, liver, and kidney (6-9). Persons who have obesity are approximately 30\% more likely to develop colorectal cancer than are persons with healthy weight (10). Women who are overweight or have obesity are approximately two to four times as likely as are women with healthy weight to develop endometrial cancer (11).

Observational studies have provided evidence that even a $5-\mathrm{kg}$ (11 pound) increase in weight since early adulthood is associated with increased risk for overweight- and obesityrelated cancers (12). Maintaining a healthy weight throughout life has been associated with a reduction in risk of these cancers (3). However, the population effect of weight loss interventions on cancer risk might not be observable for at least a decade (4). In studies evaluating the effect of weight change on risks for endometrial cancer and breast cancer after long-term follow-up, weight loss was associated with reduced risks for both types of cancer among postmenopausal women $(13,14)$. 
FIGURE 2. Average annual percent change in incidence of overweightand obesity-related cancers,* by quartile - United States, 2005-2014

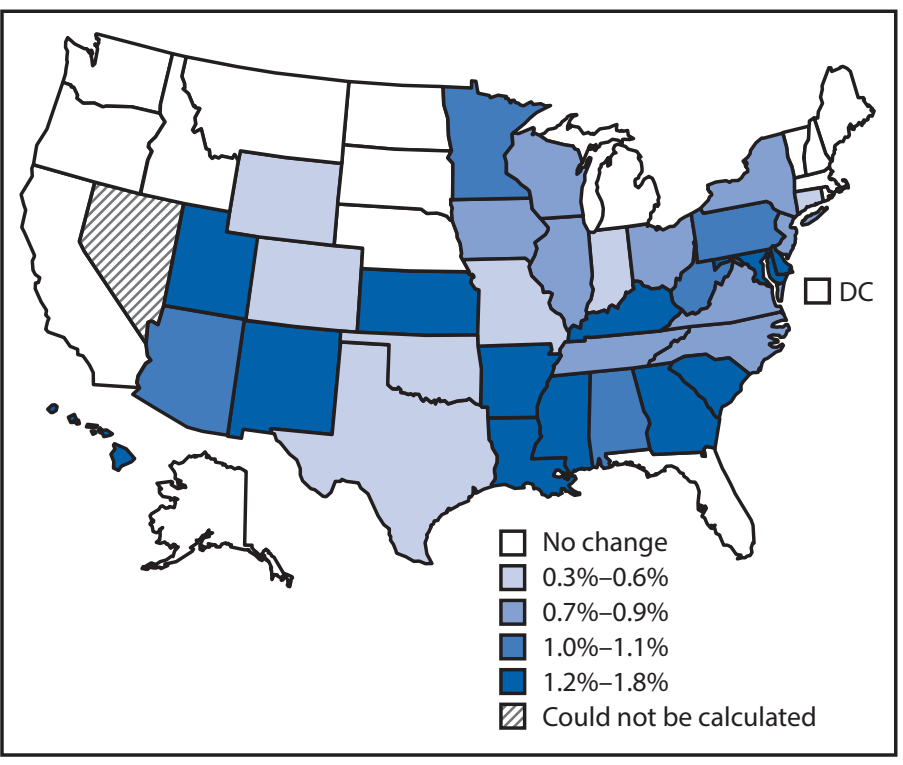

* Except colorectal cancer.

Without intensified nationwide efforts to prevent and treat overweight and obesity, the high prevalence of excess weight might impede further declines in overall cancer incidence (15). These efforts include investing in addressing both social and behavioral determinants of health, such as unemployment and disparities in education and housing, to achieve better population health (https://nam.edu/addressing-socialdeterminants-of-health-and-health-disparities-a-vital-direction-for-health-and-health-care/). Eating a healthy diet and engaging in sufficient physical activity are important components of behavioral strategies to maintain a healthy weight. Population-based strategies to prevent and reduce overweight and obesity include helping persons of all ages meet dietary (https://health.gov/dietaryguidelines/2015/guidelines) and physical activity (https://health.gov/PAGuidelines) guidelines by supporting healthy eating and active living in a variety of settings, including communities, worksites, schools, and early care and education facilities. Strategies to provide support for these settings have been recommended by a number of public health entities including CDC (https://www.cdc.gov/mmwr/ preview/mmwrhtml/rr5807al.htm), the National Academy of Medicine (16), and the Community Preventive Services Task Force (https://www.thecommunityguide.org/topic/ obesity). Health care providers could encourage patients to maintain healthy weights throughout their lifespans. To help treat obesity, the U.S. Preventive Services Task Force recommends that clinicians screen all adults for obesity and either offer patients who have obesity intensive, multicomponent behavioral interventions or refer them to programs that offer these services (https://www.uspreventiveservicestaskforce.org/ Page/Document/UpdateSummaryFinal/obesity-in-adultsscreening-and-management); similar recommendations exist for children aged $\geq 6$ years (https://www. uspreventiveservicestaskforce.org/Page/Document/UpdateSummaryFinal/ obesity-in-children-and-adolescents-screening).

The CDC's National Comprehensive Cancer Control Program supports comprehensive cancer control efforts in all 50 states, DC, eight tribes and tribal organizations, and seven U.S. territories and Pacific Island jurisdictions; these efforts include policy, systems, and environmental changes that promote physical activity and healthy food options in communities. A review of cancer control plans implemented by grantees revealed that $89 \%$ include goals or strategies related to nutrition or physical activity to reduce cancer risk, with $82 \%$ including both (17). Other CDC programs, such as the State Public Health Action's Program, address diet, physical activity, and obesity more broadly (https://www.cdc.gov/nccdphp/ dnpao/state-local-programs/state-public-health-action.html). Maintaining and strengthening these programmatic activities might help reduce the burden of overweight- and obesityrelated cancer.

The findings in this report are subject to at least five limitations. First, the weights and BMI histories of cancer patients were not known. Second, because race and ethnicity data are abstracted from medical records, they are subject to misclassification (https://www.cdc.gov/cancer/npcr/uscs/technical_notes/interpreting/race.htm). Third, whereas IARC's most recent report was used to define overweight-and obesity-related cancer, this might underestimate the actual burden, because evidence is still accumulating related to the association of overweight and obesity with other cancers (3). Fourth, many different risk factors might contribute to development of overweight- and obesity-related cancers, such as genetic mutations; chronic infections; and tobacco, hormone, and alcohol use (2). Changes in these other risks, as well as in cancer screening rates, might have affected the number of cancer cases and the trends described in this report. Finally, although this report tracks overweight- and obesity-related cancers, it does not estimate what proportion of these cancers are attributable to overweight and obesity.

The incidence of overweight- and obesity-related cancers (excluding colorectal cancer) increased significantly among persons aged 20-74 years during 2005-2014, mirroring increases of obesity observed since 1960 (1). Multilevel approaches to comprehensive cancer control that address social determinants of health and include evidence-based interventions that address healthy weight and other cancer risk factors might help reduce the burden of cancer and other chronic diseases in the United States. 


\section{Conflict of Interest}

No conflicts of interest were reported.

\begin{abstract}
${ }^{1}$ Division of Cancer Prevention and Control, CDC; ${ }^{2}$ Division of Nutrition, Physical Activity, and Obesity, CDC; ${ }^{3}$ Division of Cancer Control and Population Sciences, National Cancer Institute, Rockville, Maryland.
\end{abstract}

Corresponding author: C. Brooke Steele, bsteele1@cdc.gov, 770-488-4261.

\section{References}

1. National Center for Health Statistics. Prevalence of overweight, obesity, and extreme obesity among adults aged 20 and over: United States, 1960-1962 through 2013-2014. Hyattsville, MD: US Department of Health and Human Services, CDC, National Center for Health Statistics; 2016. https://www.cdc.gov/nchs/data/hestat/obesity_adult_13_14/ obesity_adult_13_14.htm

2. American Institute for Cancer Research. The AICR 2015 cancer risk survey report. Washington, DC: American Institute for Cancer Research; 2015. http://www.aicr.org/assets/docs/pdf/education/aicr-awarenessreport-2015.pdf

3. Lauby-Secretan B, Scoccianti C, Loomis D, Grosse Y, Bianchini F, Straif K; International Agency for Research on Cancer Handbook Working Group. Body fatness and cancer-viewpoint of the IARC Working Group. N Engl J Med 2016;375:794-8. https://doi. org/10.1056/NEJMsr1606602

4. Renehan AG, Zwahlen M, Egger M. Adiposity and cancer risk: new mechanistic insights from epidemiology. Nat Rev Cancer 2015; 15:484-98. https://doi.org/10.1038/nrc3967

5. White A, Thompson TD, White MC, et al. Cancer screening test useUnited States, 2015. MMWR Morb Mortal Wkly Rep 2017;66:201-6. https://doi.org/10.15585/mmwr.mm6608a1

6. Hoyo C, Cook MB, Kamangar F, et al. Body mass index in relation to oesophageal and oesophagogastric junction adenocarcinomas: a pooled analysis from the International BEACON Consortium. Int J Epidemiol 2012;41:1706-18. https://doi.org/10.1093/ije/dys176

7. Chen Y, Liu L, Wang X, et al. Body mass index and risk of gastric cancer: a meta-analysis of a population with more than ten million from 24 prospective studies. Cancer Epidemiol Biomarkers Prev 2013;22:1395-408. https://doi.org/10.1158/1055-9965.EPI-13-0042
8. Chen Y, Wang X, Wang J, Yan Z, Luo J. Excess body weight and the risk of primary liver cancer: an updated meta-analysis of prospective studies. Eur J Cancer 2012;48:2137-45. https://doi.org/10.1016/j. ejca.2012.02.063

9. Wang F, Xu Y. Body mass index and risk of renal cell cancer: a doseresponse meta-analysis of published cohort studies. Int J Cancer 2014;135:1673-86. https://doi.org/10.1002/ijc.28813

10. Ma Y, Yang Y, Wang F, et al. Obesity and risk of colorectal cancer: a systematic review of prospective studies. PLoS One 2013;8:e53916. https://doi.org/10.1371/journal.pone.0053916

11. Setiawan VW, Yang HP, Pike MC, et al.; Australian National Endometrial Cancer Study Group. Type I and II endometrial cancers: have they different risk factors? J Clin Oncol 2013;31:2607-18. https://doi. org/10.1200/JCO.2012.48.2596

12. Keum N, Greenwood DC, Lee DH, et al. Adult weight gain and adiposity-related cancers: a dose-response meta-analysis of prospective observational studies. J Natl Cancer Inst 2015;107:djv088. https://doi. org/10.1093/jnci/djv088

13. Luo J, Chlebowski RT, Hendryx M, et al. Intentional weight loss and endometrial cancer risk. J Clin Oncol 2017;35:1189-93. https://doi. org/10.1200/JCO.2016.70.5822

14. Eliassen AH, Colditz GA, Rosner B, Willett WC, Hankinson SE. Adult weight change and risk of postmenopausal breast cancer. JAMA 2006;296:193-201. https://doi.org/10.1001/jama.296.2.193

15. Eheman C, Henley SJ, Ballard-Barbash R, et al. Annual report to the nation on the status of cancer, 1975-2008, featuring cancers associated with excess weight and lack of sufficient physical activity. Cancer 2012;118:2338-66. https://doi.org/10.1002/cncr.27514

16. Institute of Medicine. Accelerating progress in obesity prevention: solving the weight of the nation. Washington, DC: National Academies Press; 2012.

17. Puckett M, Neri A, Underwood JM, Stewart SL. Nutrition and physical activity strategies for cancer prevention in current National Comprehensive Cancer Control Program plans. J Community Health 2016;41:1013-20. https://doi.org/10.1007/s10900-016-0184-8 